\title{
Legislación aplicable frente al plagio de productos publicitarios e importancia de su adecuada elección en los procesos judiciales
}

\section{Applicable legislation against plagiarism and the importance of its proper choice to face judicial proceedings}
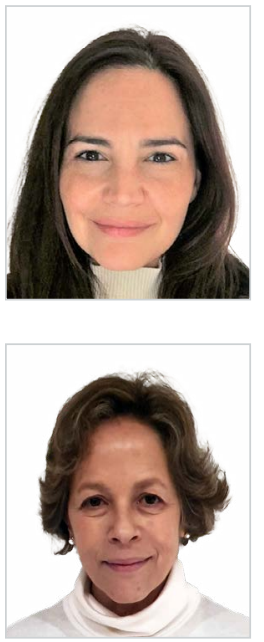

Rocío Gutiérrez Díaz. Doctora en Comunicación por la Universidad de Vigo. Ha impartido docencia de máster en la Escuela Jacobea de Postgrado. Cuenta con una amplia trayectoria profesional en medios de comunicación. Ha trabajado además como responsable de comunicación y marketing en entidades de otros sectores, siendo la más reciente la empresa francesa NFG Distribution. Su actividad investigadora está orientada al estudio del marco jurídico asociado a las marcas y otros productos publicitarios, así como a su protección extrajudicial. NFG Distribution

bi1.amont@schiever.fr

ORCID: 0000-0002-8432-9502

Pilar García Soidán. Doctora en Matemáticas por la Universidad de Santiago de Compostela. Actualmente trabaja en la Universidad de Vigo, como Catedrática de Escuela Universitaria del Departamento de Estadística e Investigación Operativa. Forma parte de los equipos de profesorado de titulaciones de grado y doctorado del ámbito de la Comunicación e imparte también docencia de máster en estudios del área de Estadística. Desarrolla su trabajo de investigación en el campo de la inferencia no paramétrica y en aplicaciones de la metodología estadística a diversos contextos. Universidad de Vigo, España pgarcia@uvigo.es

ORCID: 0000-0003-4542-6630

Recibido: 20/01/2021 - Aceptado: 22/06/2021 - En edición: 07/07/2021 - Publicado: 01/12/2021

\section{Resumen:}

El plagio es una práctica cada vez más frecuente en todos los sectores, a pesar de que actualmente está considerado a nivel jurídico como una infracción grave. En el contexto publicitario, la copia o imitación puede afectar a distintos elementos (marcas, etiquetado, etc.), y la protección jurídica de los mismos puede plantearse a través de distintas normas. En este trabajo se revisará el extenso número de leyes que serían aplicables en España frente al plagio de productos publicitarios y se indicarán algunas de sus limitaciones. Cabe destacar que la legislación
Received: 20/01/2021 - Accepted: 22/06/2021 - Early access: 07/07/2021 - Published: 01/12/2021

\section{Abstract:}

Plagiarism is an increasingly common practice in all sectors, despite the fact that it is currently considered a serious offense at the legal level. In the advertising context, copying or imitation can affect different elements (brands, labeling, etc.), and their legal protection can be raised through different rules. In this work, we will revise the extensive number of laws that could be applied in Spain against plagiarism of advertising products and some of their limitations will be indicated. It should be noted that current legislation does not protect ideas, but only their

\footnotetext{
Cómo citar este artículo:

Gutiérrez Díaz, R. y García Soidán, P. (2021). Legislación aplicable frente al plagio de productos publicitarios e importancia de su adecuada elección en los procesos judiciales. Doxa Comunicación, 33, pp. 157-177.

https://doi.org/10.31921/doxacom.n33a928
} 
actual no protege las ideas, sino solo su desarrollo, lo que afecta especialmente a aquellos ámbitos en los que la creatividad y la originalidad son factores clave para alcanzar el éxito, a la hora de captar la atención del público. Se incluirán también en esta investigación los resultados de un estudio empírico, realizado sobre una muestra de 150 demandas de supuesto plagio de productos publicitarios, que se tramitaron judicialmente en España en el período 2016-2017. Se indicarán los aspectos presuntamente plagiados, las decisiones de los órganos judiciales sobre las normas infringidas y su coincidencia con la perspectiva de la parte reclamante, así como el sentido de las resoluciones finales.

\section{Palabras clave:}

Copia; legislación; marca; plagio; publicidad. development, which especially affects those areas in which creativity and originality are key factors to achieve success, so as to capture public's attention. The current research will also include the results of an empirical study, carried out on a sample of 150 claims of alleged plagiarism of advertising products, which were judicially processed in Spain in the period 2016-2017. We will indicate the allegedly plagiarized aspects, the decisions of the judicial bodies on the infringed rules and their coincidence with the perspective of the complaining party, as well as the sign of the final resolutions.

\section{Keywords:}

Copy; legislation; brand; plagiarism; advertising.

\section{Introducción}

Según la Organización Mundial de la Propiedad Intelectual (OMPI), el plagio es el "acto de ofrecer o presentar como propia, en su totalidad o en parte, la obra de otra persona en una forma o contexto más o menos alterados" (OMPI, 1980: 192). En esta línea, investigaciones realizadas sobre el plagio aportan sus propias definiciones, de modo que lo introducen como "el apoderamiento ideal de todos o algunos elementos originalmente contenidos en la obra de otro autor presentándolos como propios" (Lipszyc, 1994: 19), "la apropiación indebida de la creación de otro" (González Gómez, 1998: 192) o "la intención de pasar las ideas, la investigación, teorías o palabras de otros como propias" (Moss, 2008: 23). Algunos autores van más allá y hacen referencia al derecho de paternidad de las creaciones, al considerar que el plagio es la "apropiación total o parcial de elementos originales de una obra ajena, en forma idéntica o simulada, con usurpación de la paternidad del verdadero autor para hacerlos pasar como propios" (Antequera, 2012: 86).

De acuerdo con las ideas expuestas, puede entenderse que una persona comete un plagio cuando copia, imita, reproduce o transforma una parte o la totalidad de alguna creación artística o intelectual, sin citar las fuentes de las que proviene o haciéndose pasar por su autor original. De cualquier forma, el plagio se ha convertido en una práctica habitual en nuestros tiempos y, en paralelo, se ha incrementado la investigación en torno a esta realidad. En el contexto académico, por ejemplo, el plagio representa una práctica cada vez más recurrente, sobre la que se han elaborado numerosos estudios. En ellos se han abordado, entre otras temáticas, los principios generales que deben respetar los trabajos realizados en el entorno académico (Toller, 2011), la clasificación de los distintos tipos de plagio detectados (Soto Rodríguez, 2012) o el análisis de la prevalencia de estas prácticas (Comas Forgas et al., 2012).

Se han encontrado asimismo investigaciones en torno al plagio en otros ámbitos, en las que se reflexiona sobre los derechos de autor o la protección de su obra, dentro del contexto literario (Gutiérrez Gutiérrez, 2010), el musical (Grilo Bartolomé, 2017) o la moda (Izquierdo Dones, 2019). También se ha estudiado esta temática en el ámbito publicitario, a través de distintos trabajos que abordan la protección de las creaciones publicitarias. Algunos de ellos ponen de manifiesto las limitaciones de regulaciones 
específicas, como en el caso de la Ley General de Publicidad (Vázquez Gestal, 2002) o de la Ley de Propiedad Intelectual (Portero Lameiro, 2017), mientras que en otros se revisan ciertas modalidades de defensa frente al plagio que ofrece la legislación actual (Tato Plaza, 2017). No obstante, en ninguna de las publicaciones mencionadas se tratan determinados supuestos, como la explotación del prestigio ajeno o la imitación, que afectan de manera sensible a la protección jurídica de los productos publicitarios, hacia los que se orienta la presente investigación. De hecho, las grandes empresas dedican una parte significativa de sus presupuestos al diseño e investigación de sus marcas y productos, pero también a la forma de presentación de los mismos a los consumidores, a través de campañas y otros recursos publicitarios. En este contexto, la creatividad es un factor indispensable para alcanzar el éxito a nivel publicitario y requiere una dotación económica importante para desarrollar los distintos elementos implicados. De ahí que la copia o imitación de los productos publicitarios resultantes supondría un grave perjuicio para las compañías y los creativos involucrados, por el aprovechamiento ajeno de sus estudios e inversiones y por la depreciación de la originalidad de sus propuestas sobre el público objetivo.

El concepto de marca ha experimentado una gran evolución a lo largo del tiempo. Actualmente la Oficina Española de Patentes y Marcas (OEPM) la define como un signo distintivo cuya "función es la de diferenciar e individualizar en el mercado unos productos o servicios de otros productos o servicios idénticos o similares, así como identificar su origen empresarial y, en cierta manera, ser un indicador de calidad y un medio de promoción de ventas" (OEPM, 2018). Para algunos autores es algo más que un identificador del producto que permite diferenciarlo del resto, puesto que consideran que representa la filosofía y organización de la propia empresa y la convierte en una garantía de calidad para el consumidor (Pettis, 1995). En este sentido, la creación de una marca sólida implica claros beneficios para su propietario, como que el propio signo se convierta en una ventaja sobre la competencia y suponga un impedimento para la inclusión de productos similares en el mercado. Este valor de marca permite, además, que el consumidor no se centre solamente en el precio a la hora de escoger un producto o servicio, sino que valore el signo como un factor más en la decisión de compra.

Al hablar de marca, es importante tener presente que la legislación actual, tanto de ámbito nacional (Ley de Marcas) como europeo (Reglamento de Marcas de la Unión Europea), diferencia entre las marcas denominativas (palabras o grupos de palabras) y las marcas gráficas (imágenes, símbolos, figuras, etc.), pudiendo afectar la infracción solamente a una de ellas o a ambas.

En la intención de los consumidores, además del producto en sí o su marca, pueden influir otros aspectos, como el etiquetado o el envasado, que informan de los beneficios y características del producto y pueden condicionar la compra. El envasado, empaque o packaging "es el conjunto de elementos visuales que permite presentar el producto al posible comprador bajo un aspecto lo más atractivo posible, transmitiendo valores de marca y su posicionamiento dentro de un mercado" (Unilever, 2002: 6). Por tanto, su diseño adquiere mucho valor, ya que "la imagen gráfica de un producto toma importancia en el empaque de un producto, que al volverse el 'vendedor silencioso' busca convencer de que es un producto que el consumidor necesita" (Pérez Espinoza, 2012: 11). En el caso del etiquetado, se puede ver como "una parte integral del empaque suele identificar al producto o marca, quién lo hizo, dónde y cuándo se hizo, cómo debe usarse y el contenido y los ingredientes del paquete" (Kerin et al., 2009: 299). Más aún, para algunos autores representa "la última oportunidad que la empresa tiene de influir en los compradores antes de que tomen la decisión de compra" (Lamb et al., 2011: 355).

En resumen, tanto la marca (principal activo de cualquier compañía), como el diseño del empaque o del etiquetado adquieren una importancia esencial en la publicidad actual, por lo que se convierten en aspectos que necesariamente hay que proteger. El 
registro de estos elementos es una buena medida contra el plagio, aunque no infalible. En este sentido, a nivel legislativo se han dado una serie de pasos para blindar las obras originales de posibles imitaciones y usos fraudulentos. De hecho, uno de los objetivos de este trabajo es la presentación de las leyes que pueden utilizarse actualmente en España en los procesos judiciales para la protección frente al plagio. A este respecto, es preciso señalar que la protección jurídica de las creaciones no se obtiene exclusivamente mediante la interposición de una demanda, ya que en ocasiones la legislación permite evitar esta vía, pero en muchos casos sí es necesario proceder de este modo. Por ello, para complementar este estudio, se realizó una investigación empírica sobre las demandas presentadas en España por presunto plagio de productos publicitarios, que estaban activas judicialmente en el bienio 2016-2017. Con este objeto y siguiendo los criterios que se detallarán en la sección 3, se diseñó un sistema de búsqueda de aquellos casos que iniciaban o continuaban su tramitación en el período indicado, sobre los cuales se analizaron las siguientes variables: los aspectos presuntamente plagiados, la legislación infringida según los organismos de tramitación y el sentido de la resolución final, para determinar hacia cuál de las partes implicadas (reclamante o reclamada) dicha resolución resultó negativa. Asimismo, interesaba conocer la perspectiva de los demandantes sobre las normas que deberían aplicarse y, particularmente, su grado de coincidencia a este respecto con la visión de los órganos judiciales, por lo que esta última variable también fue analizada en esta investigación. En este sentido, es importante tener presente que la inadecuada selección de las leyes en las que se fundamenta un presunto plagio, unida a una incorrecta argumentación o una recopilación incompleta de pruebas, entre otros factores, puede suponer para los reclamantes cierta desprotección frente a este tipo de vulneración.

\section{Legislación aplicable en España frente al plagio de productos publicitarios}

Durante buena parte de la historia, el plagio no fue considerado como una infracción legislativa, si bien era rechazado de algún modo por parte de la sociedad. No obstante, el hecho de que el plagiario solo fuera castigado con el oprobio, ralentizó mucho la aparición de una legislación centrada en esta infracción, puesto que no se evaluaba lo suficiente la gravedad que engendraba dicha vulneración (Perromat Augustin, 2010: 45). En este sentido, fue necesario esperar hasta la aparición de la Ley de Propiedad Intelectual (Ley de 10 de enero de 1879 de Propiedad Intelectual) para comenzar a disponer de un marco jurídico que otorgase protección a los derechos de los autores y de sus obras. Tras esta ley, se crearon otras normas que fueron ampliando el abanico de opciones para emprender acciones legales frente al plagio (Ley de Marcas, Ley de Competencia Desleal, Ley General de Publicidad, etc.), de aplicación en el contexto publicitario. En este sentido, es importante tener presente que el plagio de productos publicitarios puede producirse por la copia o imitación de los anuncios, los folletos, los catálogos, el esquema general, el texto, la marca o signos distintivos, las imágenes, la música, el diseño o el envasado, entre otros aspectos. Y el plagio de uno o varios de estos elementos es, precisamente, la clave a la hora de saber qué norma se está infringiendo. Así, por ejemplo, si se copia una marca o los signos distintivos de una empresa, seguramente será la Ley de Marcas la norma a la que habrá que acudir, pero si la infracción se realiza para crear confusión o aprovecharse de la reputación ajena, es probable que también se tenga que recurrir a la Ley de Competencia Desleal.

En cualquier caso, una buena forma de prevenir esta infracción es el registro de los elementos publicitarios que se quieran proteger en la Oficina Española de Patentes y Marcas (OEPM), aunque tampoco es infalible. El registro no impide que se realice una copia ilícita de un producto publicitario en cuestión. No obstante, si el creador tiene constancia de la infracción y su publicidad 
está registrada, podría dirigirse en primera instancia al organismo mencionado para proceder por la vía administrativa, cuya resolución, en cualquier caso, podría recurrir. También tendría la opción de hacer uso del arbitraje para llegar a un acuerdo entre las partes implicadas (lo que supondría no poder emprender otro tipo de acciones legales hasta obtener la resolución). De todas formas, si el resultado del arbitraje o del recurso administrativo no es satisfactorio para el interesado, este podrá ejercitar acciones civiles o penales contra cualquiera que haya vulnerado sus derechos y solicitar medidas para que estos sean protegidos (art. 52, Ley 20/2003, de 7 de julio). A partir de ahí, las principales leyes y normas a las que se puede recurrir para tramitar una infracción de plagio son:

- $\quad$ El Código Penal.

- La Ley de Propiedad Intelectual (LPI, Texto Refundido de la Ley de Propiedad Intelectual), en la que se incluye la Ley de Propiedad Industrial (PI), que a su vez contiene la Ley de Marcas (LM).

- El Reglamento sobre la Marca de la Unión Europea (RMUE).

- $\quad$ La Ley de Protección Jurídica del Diseño Industrial (LPJDI).

- $\quad$ La Ley General de la Publicidad (LGP).

- La Ley de Competencia Desleal (LCD).

- La Ley de Servicios de la Sociedad de la Información y el Comercio Electrónico (LSSI).

A pesar del amplio número de leyes indicado anteriormente, en "nuestro ordenamiento jurídico no existe un concepto jurídico de plagio preciso y unívoco que permita establecer los límites de su noción jurídica” (Manrique, 2013: 65). A este respecto, el Código Penal (Ley Orgánica 1/2015, de 30 de marzo) es la única norma que hace referencia al propio término y lo presenta como una vulneración, para la que dispone una pena de prisión ${ }^{1}$. En artículos posteriores del Código Penal se amplía este supuesto, si bien en ningún caso se aporta una definición de plagio.

La primera ley para afrontar el delito de plagio, y tal vez la más utilizada, es el Texto Refundido de la Ley de Propiedad Intelectual (LPI). Esta norma considera que "la propiedad intelectual de una obra corresponde al autor por el simple hecho de su creación" (Real Decreto Legislativo 1/1996, de 12 de abril), basándose en sus derechos personales y patrimoniales que, además, le permiten explotarla de forma legal. No obstante, en su artículo 6 se afirma que el autor será el que aparezca en la creación, con su firma, su nombre o cualquier otro signo que lo identifique. Esto podría dar lugar a cierta contradicción, ya que, aunque esta norma afirma que la propiedad intelectual es del autor que crea la obra, si ésta no está identificada con su nombre, firma o signo, sería complicado demostrar la autoría de la misma.

En cuanto a la tutela, la Ley de Propiedad Intelectual protege "todas las creaciones originales literarias, artísticas o científicas expresadas por cualquier medio o soporte, tangible o intangible, actualmente conocido o que se invente en el futuro" (Real Decreto Legislativo 1/1996, de 12 de abril). Por otra parte, la descripción del tipo de obras que pueden beneficiarse de su protección no

1 “Será castigado con la pena de prisión de seis meses a cuatro años y multa de doce a veinticuatro meses el que, con ánimo de obtener un beneficio económico directo o indirecto y en perjuicio de tercero, reproduzca, plagie, distribuya, comunique públicamente o de cualquier otro modo explote económicamente, en todo o en parte, una obra o prestación literaria, artística o científica, o su transformación, interpretación o ejecución artística fijada en cualquier tipo de soporte o comunicada a través de cualquier medio, sin la autorización de los titulares de los correspondientes derechos de propiedad intelectual o de sus cesionarios" (art. 270.1, Ley Orgánica $1 / 2015$, de 30 de marzo) 
incluye en ningún momento o categoría, las creaciones o productos publicitarios. A pesar de ello, se encargará de la infracción por plagio cuando se trate de la copia de elementos como la marca o los signos distintivos, a través de la Propiedad Industrial en general, y de la Ley de Marcas, en particular. De la misma forma, podrá aplicarse dicha norma cuando el producto publicitario pueda encuadrarse en uno de sus supuestos (por ejemplo, si en la publicidad se ha utilizado de forma ilícita una fotografía registrada o el nombre de una persona conocida, o si se han excedido los términos de un contrato de cesión o de explotación).

En cualquier caso, para poder demostrar que existe un plagio de marca o signos distintivos, se tendrán que cumplir una serie de requisitos que no solo se resumen en el parecido entre el original y la copia. En este sentido, la LM establece una serie de prohibiciones absolutas, según las cuales la marca no podrá ser registrada, ni recibir la protección de esta ley, si se trata de:

a. Los signos no susceptibles de representación gráfica y que no sirvan para distinguir en el mercado los productos de una empresa de los de otras (es decir, que no cumplan el art. 4.1, de la Ley 17/2001, de 7 de diciembre).

b. Los signos que no tengan carácter distintivo.

c. Las denominaciones compuestas únicamente por signos o indicaciones que sirvan para designar especies, calidades, cantidades, destinos, valor, etc., de los productos o servicios en el mercado.

d. Las denominaciones compuestas únicamente de signos o indicaciones que se hayan vuelto de uso habitual en el lenguaje común para designar productos o servicios.

e. Los signos compuestos por la naturaleza del producto o por la forma del mismo para conseguir un resultado técnico.

f. Los que puedan llevar a error al consumidor sobre la calidad, procedencia geográfica o naturaleza del producto o servicio.

g. Las bebidas alcohólicas que incluyan indicaciones geográficas falsas, aunque se indique el origen real del producto o se acompañe de denominaciones como tipo, estilo, clase, etc.

Asimismo, el artículo 6 de esta ley introduce diversas prohibiciones relativas y, en función de ellas, no se podrán registrar como marca:

a. Los signos que sean idénticos a una marca anterior que designe productos o servicios idénticos.

b. Los signos para los que exista un riesgo de confusión, por ser semejantes a una marca anterior o por ser similares los productos o servicios que designan.

Es importante destacar que la Oficina Española de Patentes y Marcas también podrá registrar una marca a nivel comunitario, si el propietario de dicho signo quiere obtener protección en todos los países miembros. Esta modalidad se regirá por la Ley de Marcas o, en su defecto y sin perjuicio de lo estipulado en esta última, por el Reglamento UE 2017/1001 del Parlamento Europeo y del Consejo, de 14 de junio de 2017 (RMUE), que sustituye al anterior Reglamento CE 207/2009 (RMC). El RMUE impulsó, además, la creación de una oficina de protección jurídica concreta para el derecho de marca comunitaria, denominada European Union Intellectual Property Office ${ }^{2}$ (EUIPO).

2 Oficina de Propiedad Intelectual de la Unión Europea (en español). 
Un factor adicional en la protección de la marca frente al plagio, de acuerdo con la LM, podría ser su notoriedad o renombre. Así, el artículo 8 prohíbe el registro de signos distintivos similares a otros signos españoles que fuesen conocidos ampliamente en el sector del mercado al que iban destinados sus productos o servicios (notorios) o que fuesen conocidas por el público en general (renombrados). En cualquier caso, con la última reforma de la LM (Real Decreto Ley 23/2018, de 21 de diciembre ${ }^{3}$ ), la distinción entre estos dos tipos de marcas desaparece, pasando a designarse en ambos casos como renombradas e incluyendo las marcas de cualquier estado de la Unión Europea. Otra novedad que introdujo la referida reforma fue la ampliación de la prohibición de registro de aquellos signos que imitaran la forma u otras características de los ya existentes.

En lo que se refiere a las infracciones de diseños industriales, la LPI se ocupará de ellas, aunque a su vez podrán regirse por la Ley 20/2003 de 7 de julio, de Protección Jurídica del Diseño Industrial (LPJDI, Ley 20/2003 de 7 de julio). Esta ley, que nace de la obligación de adaptarse a la normativa comunitaria y de dotar al diseño de una protección industrial acorde a sus necesidades actuales, al igual que la norma anteriormente mencionada, no otorga su protección al producto en sí mismo, sino que protege "el valor añadido por el diseño al producto desde el punto de vista comercial, prescindiendo de su nivel estético o artístico y de su originalidad" (Ley 20/2003, de 7 de julio). Esta duplicidad en la protección de los diseños industriales reafirma la idea de que no existe una legislación concreta que se ocupe de las infracciones relacionadas con el plagio y, mucho menos, con el plagio de productos publicitarios. Por otra parte, la LPI también se aplicará en los casos de infracción de los derechos de autor (derechos morales o derechos patrimoniales), para lo que se tendrá en cuenta si existen derechos de cesión y si estos se han vulnerado de alguna forma.

Centrándonos en la legislación específica en materia de publicidad y comunicación, la regulación vigente nos remite a la Ley 34/1988, de 11 de noviembre, General de Publicidad (LGP), y a la Ley 3/1991, de 10 de enero, de Competencia Desleal (LCD), normas destinadas a la regulación de la actividad publicitaria y a la represión de las infracciones en este ámbito. Estas dos leyes constituyen vías paralelas a la LPI, dando respuesta a infracciones de plagio publicitario que no encuentran la protección adecuada en la última. Además, ambas normas están interrelacionadas por lo que, en algunos casos de la publicidad ilícita, la primera de ellas nos derivará a la segunda.

La LGP ha sido la norma de referencia en esta materia, a pesar de la posterior aparición de la LCD. Esta última se encarga de regular supuestos como la publicidad engañosa, la publicidad comparativa o la publicidad desleal, además de recoger una serie de acciones por competencia desleal paralelas a las acciones por publicidad ilícita que contempla la LGP.

Ante un panorama como este, se hizo necesaria la aprobación de la Ley 29/2009, de 30 de diciembre, por la que se modifica el régimen legal de la competencia desleal y de la publicidad para la mejora de la protección de los consumidores y usuarios. De este modo se deroga por completo el título IV de la LGP sobre cesación, rectificación y acciones, a la vez que se acaba con la duplicidad de algunos supuestos. Así, a través de esta reforma, la ley mantiene los tipos de publicidad ilícita en su artículo 3, pero solamente desarrolla los que no recoge la LCD (publicidad subliminal, publicidad que atenta contra la dignidad de la persona, etc.). De esta forma, algunos supuestos de la publicidad ilícita como la publicidad desleal, la publicidad engañosa o la publicidad comparativa, se incluyen solamente en esta última.

3 Esta reforma de la Ley de Marcas supuso la trasposición al derecho español de la directiva europea relativa a la aproximación de las legislaciones en materia de marcas de los países miembros (Directiva UE 2015/2436 del Parlamento Europeo y del Consejo, de 16 de diciembre de 2015). 
Otro de los motivos que llevó a la reforma de la Ley General de Publicidad y a su promulgación fue la necesidad de adaptar dos normas comunitarias al régimen jurídico español: la Directiva sobre publicidad engañosa y publicidad comparativa (Directiva 2006/114/CE del Parlamento Europeo y del Consejo, de 12 de diciembre) y la Directiva relativa a las prácticas comerciales desleales en sus relaciones con los consumidores (Directiva 2005/29/CE del Parlamento Europeo y del Consejo, de 11 de mayo). Esto supuso que la nueva ley incorporase una definición clara y general del concepto de publicidad, presentándolo como "toda forma de comunicación realizada por una persona física o jurídica, pública o privada, en el ejercicio de una actividad comercial, industrial, artesanal o profesional, con el fin de promover de forma directa o indirecta la contratación de bienes muebles o inmuebles, servicios, derechos y obligaciones" (Ley 34/1988, de 11 de noviembre). En cuanto a la tutela de la publicidad, la LGP atribuye la protección de las creaciones publicitarias tanto a dicha norma, como a la Ley de Competencia Desleal, y a otras medidas especiales que regulen actividades publicitarias concretas (art. 1, Ley 34/1988, de 11 de noviembre). Aquí podemos comprobar una vez más como estas dos leyes están interrelacionadas y una deriva a la otra.

En el caso del plagio de productos publicitarios, el hecho de que la LCD haya asumido ciertos supuestos que, hasta el momento, eran responsabilidad de la LGP, supone que esta última no contiene actualmente muchos artículos que se adapten al objeto de estudio. Por eso, además del texto referido a la publicidad ilícita, cabe resaltar el Título III, relativo a los contratos publicitarios, que estarán bajo la tutela de su articulado y, si esto no fuera posible, se regirán por el Derecho Ordinario.

Es importante destacar que las modificaciones que introduce la Ley 29/2009 en la LCD conllevan la creación de un nuevo modelo social que divide la protección contra la competencia desleal en dos grupos. Así, a los actos de competencia desleal que ya se contemplaban, destinados a proteger los intereses privados de las empresas, se les añaden los que afectan a los consumidores. Esta reforma ofrece una protección muy importante en relación con la competencia en el mercado, prohibiendo, como recoge su artículo 1, los actos de competencia desleal, en los que se incluye la publicidad ilícita, aunque ésta esté supeditada a la Ley General de Publicidad. Para cometer una práctica desleal solo se deben cumplir dos condiciones: que ésta se lleve a cabo en el mercado (que tenga carácter externo) y que se haga con fines concurrenciales (que el acto tenga como objetivo la promoción y la afirmación de la difusión en el mercado de sus productos o los de terceros).

Los actos de confusión, recogidos en el artículo 6, se refieren al plagio, aunque en este caso, no se trata de una creación que se quiere hacer pasar como propia, sino de confundir al consumidor sobre el origen de sus actividades, creando el consiguiente riesgo de asociación con prestaciones o negocios ajenos. Es una norma prohibitiva que únicamente tiene en cuenta el comportamiento del infractor (desechando su intencionalidad) y en la que se presupone la deslealtad.

Por su parte, el artículo 10, que versa sobre actos de comparación, es el que por primera vez habla de imitación, reconociendo como prácticas desleales las imitaciones o réplicas de bienes y servicios designados por una marca o nombre comercial protegidos. En la misma línea, el artículo 11 de la LCD recoge todos los actos de imitación, pero afirma que la copia de prestaciones o iniciativas empresariales ajenas es libre, excepto si éstas están bajo la protección de algún derecho exclusivo (derechos de autor, derecho de propiedad industrial, marcas, etc.). Sin embargo, sí considera desleal la imitación de estas iniciativas "cuando resulte idóneo para generar la asociación por parte de los consumidores respecto a la prestación o comporte un aprovechamiento indebido de la reputación o el esfuerzo ajeno". 
Por este motivo, cuando se habla de imitación por aprovechamiento de la reputación ajena, la ley hace especial referencia a la imitación por reproducción, que en el ámbito publicitario podría ser la reproducción de fotografías, diseños y otros aspectos de un catálogo ajeno en uno propio. Además, se indica que este aprovechamiento de la reputación ajena debe ser ilegal o fraudulento, evitable y sin justificación. Por otra parte, también se señala como práctica desleal la imitación sistemática de los servicios y negocios de un competidor, si el objetivo de esta acción es imposibilitar que se afirme en el mercado y si sobrepasa lo que sería una respuesta natural de los consumidores. En este caso, el artículo 11 de esta ley, que se refiere a las imitaciones de creaciones materiales y de las características de los productos o servicios, tiene carácter declarativo y solo considera desleal la imitación en algunos supuestos.

Otro aspecto que aparece recogido en la legislación es la denominada publicidad adhesiva o parasitaria, que figura como supuesto de publicidad ilícita en el artículo 3a de la LGP y también se considera una práctica desleal por el aprovechamiento de la reputación ajena, como refleja el artículo 12 de la LCD. A estas dos normativas, se añade la Ley de Marcas si la imitación de la creación publicitaria es relativa a signos distintivos. En cualquier caso, si se pretende valorar si una obra publicitaria incurre en prácticas desleales, se tendrá que comprobar el grado de similitud con la creación original, prestando atención a lo relevantes y variados que sean los elementos imitados, así como a su notoriedad (que depende directamente de su distinción y difusión) y a los elementos diferenciadores que presenta. De esta forma, cuantos más elementos se copien, mayor será el parecido entre las dos creaciones, pero además se tendrá en cuenta si los elementos objeto de plagio tenían un carácter relevante en la publicidad original o si esta última presentaba un gran nivel de singularidad.

En la Ley de Competencia Desleal también se contemplan las prácticas engañosas y se diferencian dos tipos: las prácticas engañosas por confusión para los consumidores y las prácticas engañosas por confusión. Las primeras se refieren a las prácticas comerciales que "creen confusión, incluido el riesgo de asociación, con cualesquiera bienes o servicios, marcas registradas, nombres comerciales $u$ otras marcas distintivas de un competidor, siempre que sean susceptibles de afectar al comportamiento económico de los consumidores y usuarios" (art. 20, Ley 3/1991, de 10 de enero). Por su parte, las prácticas engañosas por confusión (art. 25, Ley 3/1991, de 10 de enero) se refieren a la promoción de un servicio parecido a otro que ya existe en el mercado, para hacer creer a los consumidores, de forma deliberada, que sus productos o servicios provienen de la misma empresa o profesional, aprovechándose del prestigio o la reputación ajenos.

La Ley de Marcas y la Ley de Competencia Desleal confluyen en algunos aspectos, como aquellos que se refieren a los derechos de exclusiva de la propiedad industrial. En este sentido, mientras que la primera de las normas protege los derechos subjetivos de un bien inmaterial (siempre que éste se haya registrado), la segunda tiene como objetivo el buen funcionamiento del mercado. No obstante, y aunque no es objeto de esta investigación revisar la jurisprudencia relativa al plagio, haremos referencia a una sentencia que pone de manifiesto la dificultad existente a la hora de elegir entre la LM y la LCD. Así, la aplicación de “[...] una u otra legislación, o ambas a la vez, dependerá de la pretensión de la parte actora y de cuál sea su fundamento fáctico, así como que se demuestre la concurrencia de los presupuestos de los respectivos comportamientos que han de darse para que puedan ser calificados como infractores conforme a alguna de ellas o ambas a la vez" (Audiencia Provincial de Córdoba, Sentencia del 14 de julio de 2017, p. 4). De esta forma, la jurisprudencia da a entender cierta subjetividad en la valoración de la aplicación de una u otra ley, ya que esto dependerá de las características de cada caso, que habrá que estudiar de manera independiente. 
Para finalizar esta revisión de la legislación, se debe tener presente la regulación relativa a las comunicaciones comerciales que se emiten en formato electrónico, cada vez más utilizadas para intercambiar información y realizar actividades económicas y comerciales. Concretamente, la Ley 34/2002, de Servicios de la Sociedad de la Información y el Comercio Electrónico (LSSI, Ley 34/2002, de 11 de julio) pretende regular la nueva forma de hacer publicidad a través de medios electrónicos, sin perjuicio de la protección que le otorga la LGP y la LCD. Incorporada a la legislación por la Directiva 2000/31/CE del Consejo y del Parlamento Europeo, esta norma se refiere a ciertos aspectos jurídicos de los Servicios de la Sociedad de la Información (con especial atención a los relacionados con el comercio electrónico), algunos de los cuales aluden a la copia o plagio de productos publicitarios. De todas formas, conviene aclarar que esta ley solo se encargará de aquellos aspectos que, por ser novedosos o peculiares, queden fuera de los supuestos incluidos en las demás normas vigentes en materia de publicidad. Así, su artículo 8, que versa sobre las restricciones a la prestación de servicios y procedimientos de cooperación intracomunitaria, es el primero que hace referencia a derechos exclusivos, afirmando que si se atenta contra principios como la protección de los derechos de propiedad intelectual (apartado 1e.), los organismos que regulan su protección podrán llevar a cabo ciertas medidas para interrumpir la prestación o retirar los datos infractores.

La LSSI también contempla una disposición adicional relativa a los nombres de dominio, que regula los principios del sistema de asignación de dichos nombres bajo el código de país relativo a España (.es). Esta asignación se realizará en base a las normas recogidas en la referida disposición y en el Plan Nacional de Nombres de Dominio de Internet (Orden ITC/1542/2005, de 19 de mayo), así como bajo las reglas establecidas por la autoridad de asignación o las contempladas en organismos internacionales que gestionan el sistema de nombres de dominio en internet. La entidad pública empresarial Red.es será la autoridad encargada del registro de nombres de dominio en España (según lo previsto en la disposición adicional sexta de la Ley 11/1998, de 24 de abril, General de Telecomunicaciones), pero la ley anteriormente mencionada establece la obligación de respetar los derechos de propiedad intelectual o industrial.

En resumen, el marco jurídico español ofrece una extensa legislación para ejercer acciones legales ante supuestas infracciones por plagio, particularmente en el ámbito publicitario. Este elevado número de normas puede conllevar una protección un tanto imprecisa, ya que no siempre es sencillo discernir qué ley se estaría vulnerando. De hecho, como ya se indicó anteriormente, el plagio de un producto publicitario concreto puede responder a siete leyes diferentes, dependiendo de sus características. A esto hay que añadir que las ideas no están protegidas por la ley, sino solamente su desarrollo, y que el concepto de plagio no está incluido en ninguna de las normas del ordenamiento jurídico dedicadas a esta vulneración (con excepción del Código Penal). Todo ello pone de manifiesto la enorme dificultad que entraña la selección y aplicación adecuadas de la legislación sobre plagio a la hora de afrontar esta infracción.

\section{Material y método}

Para complementar el estudio del plagio en la publicidad, se llevó a cabo una investigación de los casos de supuesta copia de productos publicitarios en España, que estaban activos judicialmente en el bienio 2016-2017. Para obtener la muestra utilizada en este trabajo, se seleccionó el período indicado de dos años, con objeto de disponer de un conjunto significativo de datos a partir de la reforma llevada a cabo en el Código Penal (Ley Orgánica 1/2015, de 30 de marzo), que introdujo como novedad la 
posibilidad de imponer penas de cárcel por la comisión de este delito. Conviene precisar que se consideró como caso activo judicialmente en 2016-2017 a todo aquel que estaba incurso en un proceso judicial en alguno de los dos años indicados.

En cuanto a la delimitación espacial del estudio, se eligió el territorio español. En este sentido, se tuvo presente que, aunque las normas comunitarias rigen también en otros estados de la Unión Europea, en cada país debe aplicarse paralelamente la legislación nacional, en aquellos supuestos en los que sea procedente. En consecuencia, con la delimitación indicada, los casos que se encontrasen corresponderían al mismo entramado jurídico y deberían responder a idénticas vulneraciones del Código Penal.

Los datos de esta investigación se obtuvieron por observación, para lo que se recurrió a distintas fuentes, con objeto de localizar las demandas activas judicialmente en el período 2016-2017, en las que se hubiese denunciado el plagio de alguno o varios de los siguientes elementos: los signos distintivos de otros anunciantes, el texto, las imágenes, el slogan, el esquema general, el diseño, la música o efectos sonoros, la apariencia comercial y la copia o imitación del producto. La fuente principal de información fue el Centro de Documentación Judicial (CENDOJ), dependiente del Consejo General del Poder Judicial, cuya base contiene los datos de todos los procesos que han tramitado los diferentes órganos judiciales a lo largo de los años y sus correspondientes resoluciones. También se utilizó la base de datos de EUIPO, que permitió localizar aquellas demandas que se tramitaron por la vía judicial de la Unión Europea. Para la búsqueda de los casos en ambas bases se utilizaron diferentes palabras clave, que hacían referencia al plagio y a otras denominaciones de las infracciones, a los diferentes productos publicitarios o a las distintas normas y derechos incluidos en las mismas. Además, se recurrió a la prensa como fuente de información y, más concretamente, a tres medios de gran repercusión mediática a nivel estatal: El País, El Mundo y ABC. La motivación para la inclusión de esta fuente fue la localización de varias noticias relacionadas con presuntos plagios de productos publicitarios en los diarios indicados. No obstante, en la mayoría de ellos no se emprendieron acciones legales o no se pudo comprobar que existiera realmente una infracción, por lo que se descartaron para el estudio. Los restantes casos se incorporaron a la muestra solamente si se podía conseguir la información de la demanda correspondiente a través de las bases de CENDOJ o EUIPO, obteniéndose de este modo tan solo el 4\% de los datos. La tabla siguiente resume la distribución de los casos según el medio de localización.

Tabla 1. Medio de localización de los casos

\begin{tabular}{|l|c|}
\hline \multicolumn{1}{|c|}{ Medio } & No de casos \\
\hline CENDOJ solamente & 144 \\
\hline CENDOJ y Prensa & 4 \\
\hline EUIPO y Prensa & 2 \\
\hline Total & $\mathbf{1 5 0}$ \\
\hline \multicolumn{2}{|c|}{ Fuente: elaboración propia } \\
\hline
\end{tabular}

Una vez seleccionada la muestra, se hizo un seguimiento de cada una de las demandas incluidas en ella hasta su resolución final, para obtener información de las distintas variables que se indican a continuación: aspecto presuntamente plagiado, leyes infringidas según los responsables judiciales, coincidencia sobre la legislación infringida (entre la parte reclamante y el organismo asignado) y sentido de la resolución final. Con los datos resultantes se elaboró una base de datos en formato Excel, que luego se analizó con los programas Excel y R-Commander para dar respuesta a los objetivos planteados en la investigación. Para ello se 
utilizó metodología cuantitativa de tipo exploratorio, con objeto de describir mediante tablas y gráficos la información obtenida para las variables del estudio. Los principales resultados se resumen en la sección siguiente.

\section{Resultados}

La muestra utilizada en esta investigación contiene las demandas por plagio de productos publicitarios, que se localizaron a través de las fuentes seleccionadas y que comenzaron o continuaron su tramitación judicial en el bienio 2016-2017. La tabla que se presenta a continuación resume la información relativa a los aspectos presuntamente plagiados.

Tabla 2. Aspectos presuntamente plagiados

\begin{tabular}{|l|c|}
\hline \multicolumn{1}{|c|}{ Aspecto presuntamente plagiado } & Porcentaje de casos \\
\hline A01-Diseño & $6,6 \%$ \\
\hline A02-Diseño/Otros aspectos & $1,3 \%$ \\
\hline A03-Etiquetado & $0,7 \%$ \\
\hline A04-Etiquetado/Marca denominativa y gráfica & $0,7 \%$ \\
\hline A05-Etiquetado/Marca denominativa/Otros signos & $0,7 \%$ \\
\hline A06-Etiquetado/Marca gráfica & $0,7 \%$ \\
\hline A07-Marca denominativa & $65,9 \%$ \\
\hline A08-Marca denominativa y gráfica & $10,6 \%$ \\
\hline A09-Marca denominativa y gráfica/Otros signos & $0,7 \%$ \\
\hline A10-Marca denominativa/Diseño & $1,3 \%$ \\
\hline A11-Marca denominativa/Otros aspectos & $0,7 \%$ \\
\hline A12-Marca denominativa/Otros signos & $2,7 \%$ \\
\hline A13-Marca gráfica & $3,3 \%$ \\
\hline A14-Otros aspectos & $0,7 \%$ \\
\hline A15-Otros signos & $0,7 \%$ \\
\hline A16-Packaging & $2,7 \%$ \\
\hline Total & $\mathbf{1 0 0 \%}$ \\
\hline
\end{tabular}

Fuente: elaboración propia

Los resultados anteriores muestran que la marca, ya sea denominativa o gráfica, es el aspecto incluido mayoritariamente en las demandas por plagio $(87,3 \%)$ y, particularmente la marca denominativa $(83,3 \%)$, a gran distancia de la marca gráfica (16\%) o el diseño (9,2\%). Esto significa que, casi todos los casos analizados, deberían haber apelado a la Ley de Marcas o al Reglamento de Marca de la Unión Europea (si se tratase de una marca comunitaria) para la tramitación de estas infracciones. No obstante, en algunas de estas situaciones se incurrió en el plagio de más de un elemento (8,8\%), por lo que el mismo caso podría vulnerar varias leyes a la vez. 
En la práctica, además de los aspectos sobre los que se haya podido incurrir en alguna infracción, es importante tener en cuenta también el contexto que envuelve a cada situación particular, para poder establecer las normas vulneradas. En este sentido, el gráfico siguiente recoge la perspectiva de los organismos de tramitación, sobre las leyes infringidas en los litigios incluidos en la muestra.

Figura 1. Legislación infringida según el organismo de tramitación

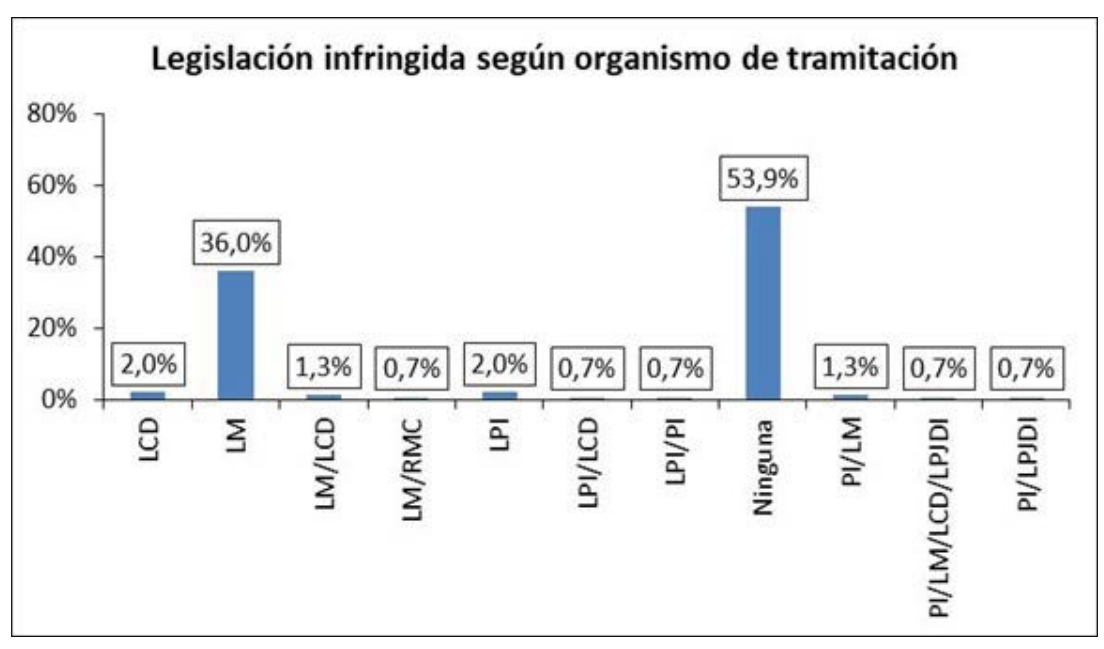

Fuente: elaboración propia

Como se puede observar, los órganos receptores de las demandas consideraron que no existió infracción en más de la mitad de ellas (53,9\%). Cabe destacar también que, de acuerdo con el criterio de dichos organismos, la norma más vulnerada fue la Ley de Marcas (40\%), seguida con una gran diferencia por la Ley de Competencia Desleal (5,1\%), la Ley de Propiedad Intelectual o la de Propiedad Industrial (infringidas en el 3,4\% de los conflictos cada una de ellas), y la Ley de Protección Jurídica del Diseño Industrial $(1,4 \%)$. Por otra parte, teniendo en cuenta que tanto la Ley de Propiedad Industrial como la Ley de Marcas forman parte de la LPI y contabilizando conjuntamente todos los casos, se podría concluir con que esta última estuvo presente en el 44,1\% de las demandas estudiadas. En la misma línea, dado que la Ley de Marcas está incluida en la Ley de Propiedad Industrial, los organismos asignados consideraron que en el $41,4 \%$ de las denuncias se detectaron vulneraciones a esta última norma.

Para conocer con más detalle las leyes en las que se apoyaron los responsables judiciales para emitir sus resoluciones sobre los casos tramitados, la Tabla 3 refleja esta información, desagregada para los diferentes aspectos sobre los que se presentaron las demandas por plagio. 
Tabla 3. Legislación infringida según los órganos judiciales para cada aspecto presuntamente plagiado (incluyendo solo aquellos aspectos con más de dos casos)

\begin{tabular}{|c|c|c|c|c|c|c|}
\hline \multirow{2}{*}{$\begin{array}{c}\text { Ley infringida según los } \\
\text { órganos judiciales }\end{array}$} & \multicolumn{6}{|c|}{ Aspecto presuntamente plagiado } \\
\hline & A01 & A07 & A08 & A12 & A13 & A16 \\
\hline LCD & $10,0 \%$ & & $6,2 \%$ & & & \\
\hline LM & & $42,5 \%$ & $43,8 \%$ & $25,0 \%$ & $40,0 \%$ & $25,0 \%$ \\
\hline LM/LCD & & $2,0 \%$ & & & & \\
\hline $\mathrm{LM} / \mathrm{RMC}$ & & & & & $20,0 \%$ & \\
\hline LPI & $10,0 \%$ & & & & & \\
\hline LPI/LCD & & $1,0 \%$ & & & & \\
\hline LPI/PI & $10,0 \%$ & & & & & \\
\hline Ninguna & $50 \%$ & $54,5 \%$ & $50,0 \%$ & $75,0 \%$ & $40,0 \%$ & $75,0 \%$ \\
\hline $\mathrm{PI} / \mathrm{LM}$ & & & & & & \\
\hline PI/LM/LCD/LPJDI & $10,0 \%$ & & & & & \\
\hline PI/LPJDI & $10,0 \%$ & & & & & \\
\hline Total & $100 \%$ & $100 \%$ & $100 \%$ & $100 \%$ & $100 \%$ & $100 \%$ \\
\hline
\end{tabular}

Fuente: elaboración propia

Estos resultados confirman que la tendencia dominante, en los distintos supuestos de plagio, fue la desestimación de las demandas por parte de los organismos de tramitación, al considerar que no se infringía ninguna ley (los porcentajes oscilan entre el 40\% y el 75\% para los distintos aspectos considerados). De los casos en los que sí se observó la vulneración de alguna legislación, destacan particularmente los que aducían plagio en el diseño, por la variedad de normas a las que recurrieron los órganos judiciales para emitir sus resoluciones. En las restantes situaciones en las que se detectó alguna infracción, los organismos responsables se apoyaron en la Ley de Marcas, como era esperable dado que la marca (denominativa o gráfica) figura como el principal objeto de las denuncias, aunque también aludieron a esta norma en alguna demanda por plagio en el packaging (25\% de estos casos).

En este estudio también interesó analizar la visión de la parte reclamante sobre las normas que consideró vulneradas y que utilizó como fundamento para el planteamiento de sus demandas. A este respecto, se observó un grado importante de discrepancia con la perspectiva de los órganos judiciales, según se desprende de la Figura 2. 
Figura 2. Grado de coincidencia sobre la legislación infringida entre la parte reclamante y el organismo de tramitación

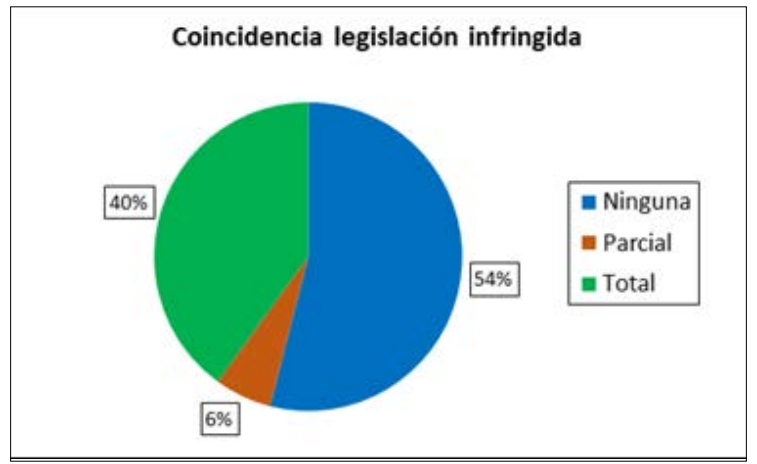

Fuente: elaboración propia

De hecho, en más de la mitad de los casos (54\%), hubo un total desacuerdo, entre la parte demandante y el organismo responsable, sobre las leyes que podían aplicarse para la resolución de las denuncias presentadas. En el $40 \%$ de los litigios hubo coincidencia absoluta sobre la legislación infringida, mientras que esa similitud de criterios entre el organismo de tramitación y la parte reclamante solamente fue parcial en los restantes casos (6\%).

Para establecer si el nivel de concordancia se mantuvo en los distintos supuestos denunciados, se muestran en la Figura 3 los porcentajes de casos en los que hubo coincidencia total sobre las leyes vulneradas, para los diferentes aspectos que se consideraban plagiados.

Figura 3. Porcentaje de coincidencia total sobre la legislación infringida para cada aspecto presuntamente plagiado (incluyendo solo aquellos aspectos con más de dos casos)

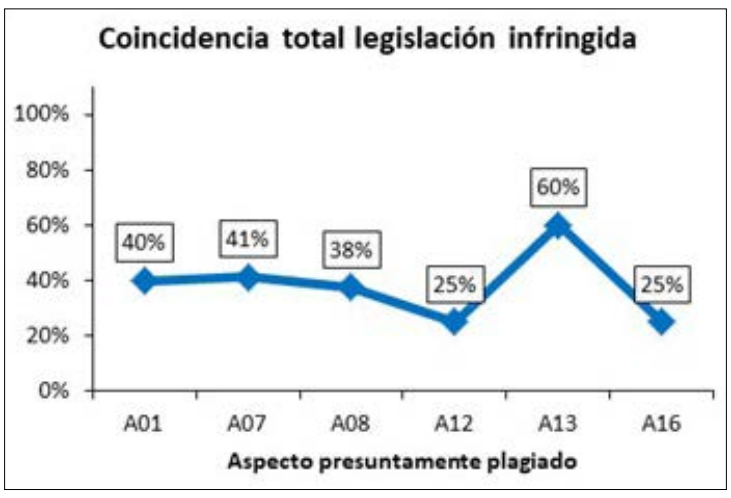

Fuente: elaboración propia 
Si bien para algunos de los supuestos aspectos plagiados parece mantenerse la pauta de concordancia total que se había detectado para la muestra en su conjunto, en torno al $40 \%$, para otros ese porcentaje incluso se reduce hasta el $25 \%$, como ocurre cuando el único elemento incluido en la demanda es el packaging. La única excepción a este nivel de discordancia se puede observar en los litigios que afectaban a la marca gráfica, en los que ambas perspectivas coincidieron en la legislación que se había vulnerado en el $60 \%$ de los casos.

Otra de las variables consideradas en esta investigación se refería al sentido de las resoluciones finales emitidas por los organismos de tramitación, con objeto de especificar a cuál de las partes implicadas en la demanda (reclamante y reclamada) afectaba negativamente la sentencia dictada en el proceso judicial. Los resultados obtenidos se resumen en el gráfico siguiente.

\section{Figura 4. Parte de la demanda para la que ha sido negativa la resolución final}

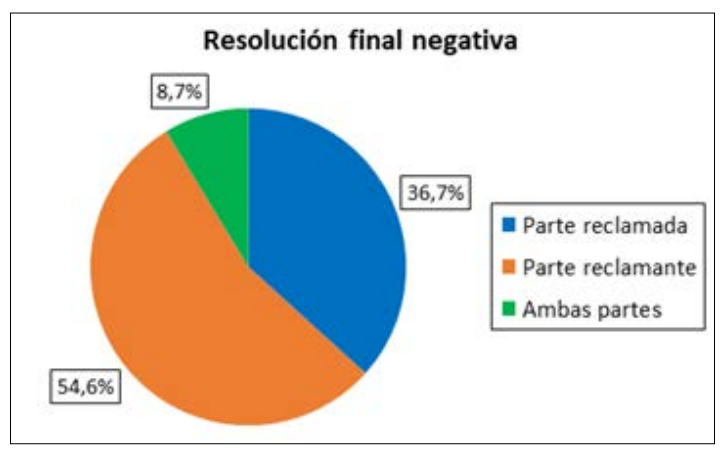

Fuente: elaboración propia

Del total de conflictos que conformaron este estudio, la parte reclamante es la que se ha visto más perjudicada por los resultados de las resoluciones $(54,6 \%)$, mientras que ha sido negativa para el agente reclamado en menor proporción (36,7\%). En las situaciones restantes, el resultado de las sentencias ha afectado a ambas partes (9\%).

Cabe destacar que, en los casos que resultaron negativos para la parte reclamante, se desestimaron sus pretensiones, que podían incluir la percepción de alguna indemnización, la prohibición del uso ajeno de algún elemento o recurso publicitario que consideraba propio, etc. Es más, en esas situaciones el demandante tuvo que hacerse cargo total o parcialmente de las costas y aceptar que la parte reclamada pudiese seguir utilizando o explotando la publicidad supuestamente ilícita. En lo que respecta a las resoluciones desfavorables para el demandado, las consecuencias más habituales se enfocaron a la prohibición del uso y explotación de los elementos plagiados (mediante su retirada del mercado, destrucción, embargo, etc.), al pago de indemnizaciones a los reclamantes o incluso a la publicación de la sentencia final en algún medio de comunicación.

Para concluir este estudio, se presenta en la Figura 5 la información sobre el sentido de las resoluciones finales emitidas por las autoridades judiciales, desagregada según el grado de coincidencia sobre la legislación infringida (entre los organismos responsables y los reclamantes). 
Figura 5. Parte de la demanda para la que ha sido negativa la resolución final en función de la coincidencia sobre la legislación infringida entre el reclamante y el órgano judicial

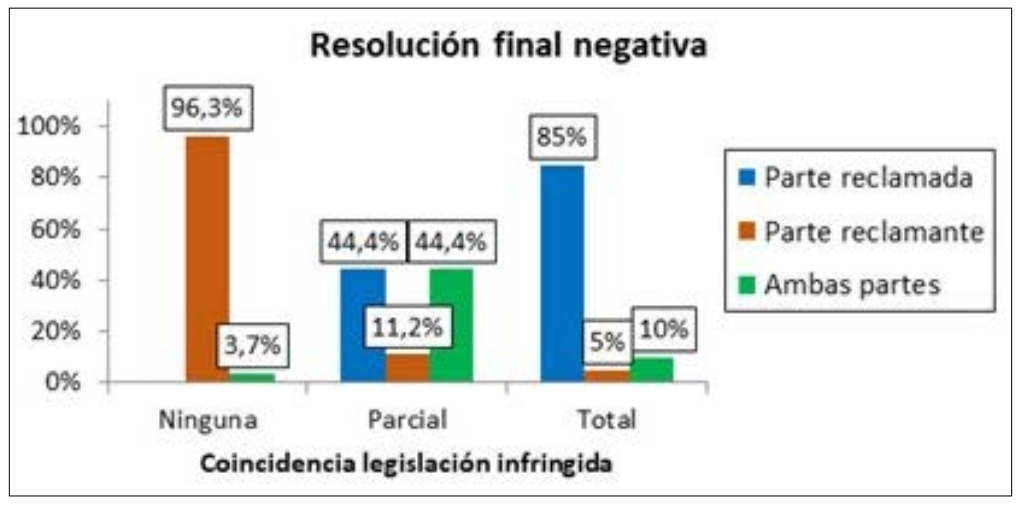

Fuente: elaboración propia

La concordancia (entre los responsables judiciales y los reclamantes) sobre las normas que debían aplicarse, se tradujo en resoluciones negativas hacia la parte reclamada, como era esperable. De hecho, en las situaciones en las que hubo acuerdo total, los resultados fueron mayoritariamente desfavorables para las personas demandadas (en el 85\% de los litigios). Cuando las perspectivas sobre la legislación infringida coincidieron parcialmente, aumentaron ligeramente las sentencias que perjudicaban a la parte reclamante, mientras que los restantes resultados negativos se repartieron equitativamente entre aquellos que afectaban al reclamado únicamente o a ambas partes. Esta pauta cambia radicalmente en las demandas en las que hubo discordancia absoluta sobre las leyes que debían aplicarse, que se resolvieron contrariamente a la parte reclamante, en casi la totalidad de ellas $(96,3 \%)$.

\section{Discusión y conclusiones}

A partir de la información analizada en esta investigación, queda patente la inexistencia de una definición clara del concepto de plagio y de una ley concreta que recoja todos los supuestos de esta infracción. Sobre esto último, se ha puesto de manifiesto que las demandas por plagio se podrían tramitar a través de siete normas, que confluyen entre ellas en algunos supuestos. A ello se une el hecho de que, según la jurisprudencia, cada caso tendrá que estudiarse de forma individual, lo que dificulta el trabajo de los representantes legales a la hora de encuadrar adecuadamente la supuesta infracción en la legislación vigente y, por tanto, puede provocar cierta indefensión frente a este delito. En cualquier caso, se debe tener presente que las resoluciones alcanzadas por los organismos asignados no sólo se basan en la ley infringida, sino que tienen en cuenta otros factores, como pueden ser las resoluciones en firme de los tribunales que han sentado precedente.

En el contexto publicitario, el problema se agrava aún más ante la falta de una reglamentación que proteja de forma específica las obras y creaciones en este ámbito. De hecho, aunque a priori parece que se podría recurrir con este objeto al derecho de autor, no están regulados los requisitos que deben cumplir las creaciones publicitarias para acceder a su tutela (Tato Plaza, 2017). 
Otro problema detectado es que la protección de la ley se refiere a las obras y creaciones, pero no a las ideas en las que se fundamentan, lo que añade indefensión cuando se trata de las campañas publicitarias, puesto que, en la mayoría de los casos, la idea es el centro de las mismas. Por otra parte, si se tienen presentes los parámetros recogidos en la legislación para determinar si se incurre en delito de plagio (signos distintivos, texto, diseño, etc.), no parece difícil evitar estas limitaciones y proceder a copiar una obra sin incurrir en una práctica ilícita.

Una de las normas a la que más se recurre en presuntas infracciones por plagio es la LPI. En ella se reconocen ciertos derechos que tiene el autor sobre su obra por haberla creado, si bien la problemática de intentar defenderla cuando no está registrada, pone de relieve que no es tan sencillo demostrar la autoría. De la misma forma, el hecho de que la obra tenga que haberse publicado en algún soporte para recibir su tutela, da como resultado una desprotección total para aquellas creaciones que todavía no han visto la luz. Por otra parte, esta norma proporciona una protección muy similar a la que ofrece la LPJDI ante una infracción relativa al diseño publicitario, lo que dificulta su adecuada aplicación, ya que elegir entre ellas puede suponer una ardua tarea de interpretación y de revisión de la jurisprudencia.

La LM es una de las leyes más completas para tramitar infracciones marcarias, si bien requiere también el registro de la marca para poder recibir su tutela, con la excepción de las marcas renombradas. Por su parte, la LCD trató de cubrir el vacío existente en la legislación relativo a las prácticas desleales, si bien algunos supuestos de esta norma han creado controversia. En particular, cabe mencionar el hecho de que considere libre la imitación de prestaciones o iniciativas empresariales o que la copia de una creación sea lícita si no hay riesgo de confusión. Asimismo, diferencia entre intereses colectivos de los consumidores e intereses privados de las empresas, por lo que las prácticas comerciales tendrán que enfrentarse a un doble régimen jurídico. La LCD comparte algunos supuestos con otras leyes, como la LGP o la LM, por lo que su aplicación requerirá un análisis pormenorizado de la situación, si se quiere ofrecer una protección adecuada frente al delito.

El estudio empírico llevado a cabo ha puesto de manifiesto la elevada tasa de incidencia de los conflictos por plagio, a la vista del número de demandas recopiladas para la presente investigación, máxime teniendo en cuenta que se localizaron en un período en el que ya podían recibir penas de cárcel los delitos de este tipo. Por otra parte, ha quedado patente que el aspecto que más se trata de imitar es la marca y en ella se centraron casi todas las reclamaciones. En cambio, fueron mucho menos habituales las situaciones en las que se aludía a vulneraciones relativas al diseño, el etiquetado o el packaging. Teniendo esto presente, parece razonable que la Ley de Marcas fuese la legislación infringida con más frecuencia, según el criterio de los organismos de tramitación, si bien sorprende que en una proporción mayor rechazasen las reivindicaciones planteadas por los demandantes, en base a alguna de las leyes indicadas. De hecho, las resoluciones finales resultaron negativas para los agentes reclamados en un rango inferior al 37\%, mientras que para los reclamantes lo fueron en más del 54\% de los casos. Se evidencia de este modo la dificultad que supone demostrar la existencia de un plagio y que la similitud entre dos creaciones no es prueba suficiente para validar la infracción. Además, el hecho de fundamentar las demandas en las normas más apropiadas se revela como otro aspecto clave para que los órganos judiciales coincidan con la perspectiva de los reclamantes y emitan resoluciones favorables a los mismos. Sin embargo, los datos recogidos muestran que en más de la mitad de los casos hubo un desacuerdo total sobre la legislación vulnerada, aunque las demandas en las que la marca gráfica fue el aspecto presuntamente plagiado, fueron las que presentaron un porcentaje de coincidencia algo más elevado. 
En cualquier caso, la gran discrepancia observada entre los reclamantes y los responsables judiciales pone de manifiesto la dificultad que supone discernir la legislación que se estaría infringiendo. A ello contribuye la existencia de un amplio número de normas para afrontar un presunto delito de plagio, con supuestos que podrían solaparse y que requerirían una interpretación apropiada para su adecuada selección. En el caso de los productos publicitarios el problema es aún mayor, ya que no se dispone de ninguna ley específica para este ámbito y la legislación existente no se ajusta a sus particularidades. No obstante, no podemos perder de perspectiva que en los resultados de los procesos judiciales también influyen otras variables, como la argumentación utilizada para el planteamiento de la infracción o la aplicación que se hubiese hecho de los elementos presuntamente utilizados de forma ilícita, que serán objeto de estudio en futuras investigaciones.

\section{Agradecimientos}

Este artículo ha sido revisado para su versión en inglés por Karen Joan Duncan.

\section{Referencias bibliográficas}

\section{Libros, monografías y publicaciones científicas}

Antequera, R. (2012). Derechos intelectuales y derecho a la imagen en la jurisprudencia comparada. Madrid: Reus.

Comas Forgas, R.; Sureda Negre, J.; Trobat, M. O. (2011). Prácticas de citación y plagio académico en la elaboración textual del alumnado universitario. Teoría de la Educación. Educación y Cultura en la Sociedad de la Información, 12(1), 359-385. DOI: https://doi.org/10.14201/eks.7837

González Gómez, A. (1998). El tipo básico de delitos contra la Propiedad Intelectual. Madrid: Tecnos.

Grilo Bartolomé, F. (2017). Historia, evolución y otras cuestiones sobre el plagio musical. Trabajo fin de máster. Máster Universitario de Acceso a la Profesión de Abogado. Universidad de Alcalá de Henares.

Gutiérrez Gutiérrez, A. (2010). El plagio literario. Quadernos de criminología, 10, 30-35.

Izquierdo Dones, S. (2019). ¿Proteger los diseños con propiedad intelectual o emplear la copia como modo de publicidad? Trabajo fin de grado. Grado en Derecho y Grado en Administración y Dirección de Empresas. Facultad de Derecho. Universidad Pontificia de Comillas.

Kerin, R., Hartley, S.; Redelius, W. (2009). Marketing. Madrid: McGraw-Hill Interamericana.

Lamb, C. W.; Hair, J. F.; McDaniel, C. (2011). Marketing. México: Cengage Learning.

Lipszyc, D. (1994). Violaciones a los derechos de autor y los derechos conexos. Sanciones civiles y penales. Seminario Regional de la Organización Mundial de la Propiedad Intelectual (OMPI) sobre derecho de autor y derechos conexos para jueces de Centroamérica, Panamá y Costa Rica, 2-4 Marzo de 1994, San José, Costa Rica.

Manrique, E. (2013). El plagio, flagelo de nuestros días. In Iure, 1(3), 62-81. Disponible en: https://revistaelectronica.unlar.edu.ar/ index.php/iniure/article/view/186/181 
Moss, S. (2008). Una historia del plagio (no mi propio trabajo). Cultura Científica y Tecnológica, 5(25), 23-24. Disponible en: http://erevistas.uacj.mx/ojs/index.php/culcyt/article/view/407/387

OEPM (2018). ¿Qué es y para qué sirve una marca? Madrid: Oficina Española de Patentes y Marcas. Disponible en: http://www. oepm.es/es/signos_distintivos/marcas_nacionales/mas_informacion/informacion_marcas_nombres/que_es_marca.html

OMPI (1980). Glosario de derecho de autor y derechos conexos. Ginebra: Organización Mundial de la Propiedad Intelectual. Disponible en: https://www.wipo.int/edocs/pubdocs/es/wipo_pub_816.pdf

Pérez Espinoza, C. K. (2012). Empaques y embalajes. México: Red Tercer Milenio.

Perromat Augustin, K. (2010). El plagio en las literaturas hispánicas: Historia, Teoría y Práctica. [Tesis de doctorado no publicada]. París: Université Paris-Sorbonne - Paris IV.

Pettis, C. (1995). Technobrands. How to create and use Brand identity to market, advertise and sell technology products. New York: American Management Association.

Portero Lameiro, J. M. (2017). La propiedad intelectual sobre las obras publicitarias: Hacia una nueva configuración legislativa en España. Madrid: Dykinson.

Soto Rodríguez, A. (2012). El plagio y su impacto a nivel académico y profesional. E-Ciencias de la Información, 2(1). DOI: https:// doi.org/10.15517/eci.v2i1.1213

Tato Plaza, A. (2017). La protección de las creaciones publicitarias. InDret: Revista para el Análisis del Derecho, 1. Disponible en: https://raco.cat/index.php/InDret/article/view/318302/408360

Toller, F. M. (2011). Propiedad intelectual y plagio en trabajos académicos y profesionales. Revista de la Propiedad inmaterial, 15, 85-97. Disponible en: https://revistas.uexternado.edu.co/index.php/propin/article/view/3000/2644

Unilever (2002). Packaging: La decisión en 5". Vilanova i La Geltru: Icon Comunicación Visual. Disponible en: https:// gasparbecerra.files.wordpress.com/2008/11/decision_5.pdf

Vázquez-Gestal, M. (2002). Limitaciones al derecho de autor en la Ley General de Publicidad y el Estatuto de la Publicidad. Zer: Revista de estudios de comunicación, 7(13). Disponible en: https://ojs.ehu.eus/index.php/Zer/article/view/6034/5716

\section{Legislación, normativas y sentencia}

Audiencia Provincial de Córdoba (2017). Sentencia de la Audiencia Provincial de Córdoba (Sección 1a) del 14 de julio de 2017. SAP CO 666/2017. Disponible en: http://www.poderjudicial.es/search/contenidos.action?action=contentpdf\&databasematch=AN\&reference=8184588\&links=DUFFIN\%20DAGELS\&optimize $=20171027 \&$ publicinterface $=$ true

Directiva 2000/31/CE del Parlamento Europeo y del Consejo, de 8 de junio de 2000, relativa a determinados aspectos jurídicos de los servicios de la sociedad de la información, en particular el comercio electrónico en el mercado interior. Disponible en: http:// data.europa.eu/eli/dir/2000/31/oj

Directiva 2005/29/CE del Parlamento Europeo y del Consejo, de 11 de mayo, relativa a las prácticas comerciales desleales de las empresas en sus relaciones con los consumidores en el mercado interior. Disponible en: http://data.europa.eu/eli/dir/2005/29/oj 
Directiva 2006/114/CE del Parlamento Europeo y del Consejo, de 12 de diciembre, sobre publicidad engañosa y publicidad comparativa. Disponible en: http://data.europa.eu/eli/dir/2006/114/oj

Directiva UE 2015/2436 del Parlamento Europeo y del Consejo, de 16 de diciembre de 2015, relativa a la aproximación de las legislaciones de los Estados miembros en materia de marcas. Disponible en: http://data.europa.eu/eli/dir/2015/2436/oj

Ley de 10 de enero de 1879 de Propiedad Intelectual. Disponible en: https://boe.es/datos/pdfs/BOE/1879/012/A00107-00108. pdf

Ley 34/1988, de 11 de noviembre, General de la Publicidad. Disponible en: https://www.boe.es/eli/es/1/1988/11/11/34/con

Ley 3/1991, de Competencia Desleal. Disponible en: https://www.boe.es/eli/es/1/1991/01/10/3/con

Ley 11/1998, de 24 de abril, General de Telecomunicaciones. Disponible en: https://www.boe.es/eli/es/1/1998/04/24/11

Ley 17/2001, de 7 de diciembre, de Marcas. Disponible en: https://www.boe.es/eli/es/1/2001/12/07/17/con

Ley 34/2002, de 11 de julio, de Servicios de la Sociedad de la Información y del Comercio Electrónico. Disponible en: https:// www.boe.es/eli/es/1/2002/07/11/34/con

Ley 20/2003, de 7 de julio, de Protección Jurídica del Diseño Industrial. Disponible en: https://www.boe.es/eli/ es/1/2003/07/07/20/com

Ley 29/2009, de 30 de diciembre, por la que se modifica el régimen legal de la competencia desleal y de la publicidad para la mejora de la protección de los consumidores y usuarios. Disponible en: https://www.boe.es/eli/es/1/2009/12/30/29

Ley Orgánica 1/2015, de 30 de marzo, por la que se modifica la Ley Orgánica 10/1995, de 23 de noviembre, del Código Penal. Disponible en: https://www.boe.es/eli/es/lo/2015/03/30/1

Orden ITC/1542/2005, de 19 de mayo, que aprueba el Plan Nacional de nombres de dominio de Internet bajo el código de país correspondiente a España («.es»). Disponible en: https://www.boe.es/eli/es/o/2005/05/19/itc1542

Real Decreto Legislativo 1/1996, de 12 de abril, por el que se aprueba el Texto Refundido de la Ley de Propiedad Intelectual, regularizando, aclarando y armonizando las disposiciones legales vigentes sobre la materia. Disponible en: https://www.boe.es/ eli/es/rdlg/1996/04/12/1/com

Real Decreto Ley 23/2018, de 21 de diciembre, de transposición de directivas en materia de marcas, transporte ferroviario y viajes combinados y servicios de viaje vinculados. Disponible en: https://www.boe.es/eli/es/rdl/2018/12/21/23

Reglamento CE 207/2009, de 26 de febrero, de Marca Comunitaria. Disponible en: http://data.europa.eu/eli/reg/2009/207/oj

Reglamento UE 2017/1001 del Parlamento Europeo y del Consejo, de 14 de junio, sobre la marca de la Unión Europea. Disponible en: http://data.europa.eu/eli/reg/2017/1001/oj 
